\title{
Bronchopleural fistula after bilateral sequential lobar lung transplantation: Technical details of a successful repair
}

\author{
Alex D’Angelo, BA, Jay K. Bhama, MD, Maria Crespo, MD, Joseph Pilewski, MD, \\ Norihisa Shigemura, MD, PhD, Christian Bermudez, MD, James D. Luketich, MD, and \\ Jonathan D'Cunha, $\mathrm{MD}, \mathrm{PhD}$, Pittsburgh, $\mathrm{Pa}$
}

We have used lobar lung transplantation (LTX) successfully in a series of patients with small chest cavities who otherwise may not have received transplantation. ${ }^{1}$ Fortunately, bronchopleural fistula (BPF) from stump dehiscence is a relatively rare occurrence after lobar LTX. A variety of well-known treatment approaches have been described when applied to other pulmonary resections. ${ }^{2}$ Drawing from this experience, we report an approach that resulted in a successful repair.

\section{CLINICAL SUMMARY}

A 60-year-old woman with idiopathic pulmonary fibrosis was listed for LTX. She had a progressively worsening course, requiring admission to the intensive care unit for worsening dyspnea. Because of her short stature with small thoracic cavities, she was offered lobar LTX with hopes of performing transplantation sooner. She underwent bilateral lobar LTX via bilateral antero-axillary mini-thoracotomies. A 10-inch taller male donor was used, transplanting the upper and middle lobes on the right and upper lobe on the left. The lower lobe bronchial stumps of the transplanted lungs were divided using an Endo-GIA stapler (Covidien, Manchester, Mass) fitted with a green load and Seamguard reinforcements (W.L. Gore \& Associates Inc, Flagstaff, Ariz). The divided airways were buttressed using donor pericardial tissue as described by our group. ${ }^{1}$ There were no intraoperative complications, and she did well initially.

One month after LTX, pulmonary infiltrates and respiratory failure developed in the patient. Flexible bronchoscopy confirmed a BPF at the right lower lobe staple line where lobectomy was performed (Figure 1). Given the severity of illness, the patient was prepared for the operating room. Under general anesthesia (single-lumen endotracheal

\footnotetext{
From the Department of Cardiothoracic Surgery, University of Pittsburgh Medical Center, Pittsburgh, Pa.

Disclosures: Joseph Pilewski reports consulting fees from Vertex. James D. Luketich reports equity in Intuitive Surgical. All other authors have nothing to disclose with regard to commercial support.

Received for publication Sept 14, 2014; revisions received Dec 8, 2014; accepted for publication Dec 12, 2014; available ahead of print Jan 23, 2015.

Address for reprints: Jonathan D'Cunha, MD, PhD, Department of Cardiothoracic Surgery, University of Pittsburgh Medical Center, UPMC Presbyterian, Suite C-900, 200 Lothrop St, Pittsburgh, PA 15213 (E-mail: dcunhaj@upmc.edu).

J Thorac Cardiovasc Surg 2015;149:e67-8

$0022-5223 / \$ 36.00$

Copyright (c) 2015 by The American Association for Thoracic Surgery

http://dx.doi.org/10.1016/j.jtcvs.2014.12.029
}

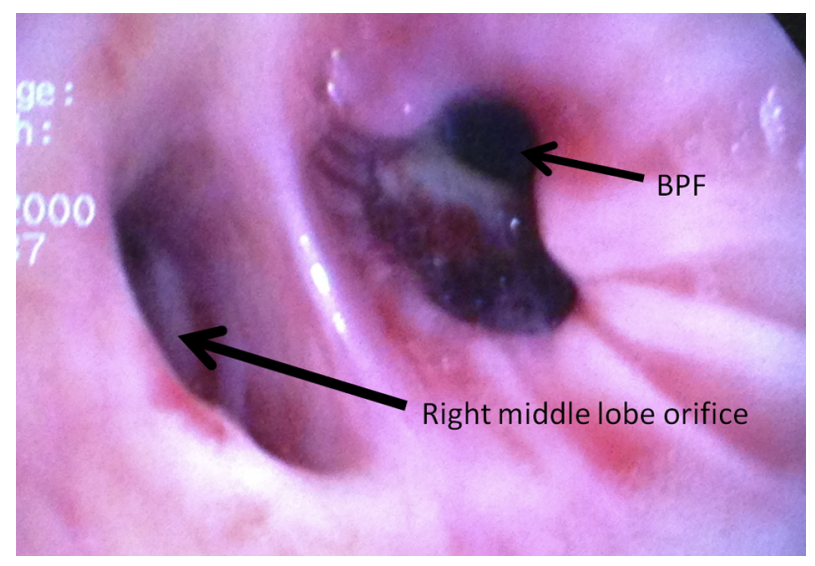

FIGURE 1. Bronchopleural fistula $(B P F)$. Preoperative bronchoscopy showing BPF at the site of right lower lobectomy (arrow labeled BPF demonstrates complete dehiscence of the staple line).

tube) with arterial and central lines placed, a midline laparotomy was performed and the greater omentum was harvested. The omental flap was prepared preserving blood supply from the right gastroepiploic artery. Under direct vision, a substernal tunnel was created from the abdomen to the sternal angle of Louis, where the omental flap was deposited for later use. A feeding jejunostomy tube was placed. We closed the abdomen and performed a right posterolateral thoracotomy along the bed of the seventh rib. An intercostal muscle flap was prepared. The chest was decorticated, and the fistula was repaired primarily (4-0 interrupted polypropylene sutures pledgeted with bovine pericardium). We acknowledge that other options to bovine pericardium exist. Autologous pericardial tissue was not suitable because of mediastinal inflammation. The right lower lobe bronchus was then buttressed using the intercostal muscle flap attached with 4-0 polyglactin interrupted sutures. There was no leak with ventilation to $35 \mathrm{~cm}$ of pressure. The substernal plane was opened anteriorly. The omental flap was brought into position overlaying the intercostal flap and secured with 4-0 polyglactin interrupted sutures. Chest tubes were placed, including a drain near the repair. The chest was closed, and Doppler signal was present in both flaps at closure. Bronchoscopy and radiography showed an intact repair with good lung reexpansion (Figure 2).

The patient's postoperative hospital stay was complicated by acute renal failure. At discharge, she had recovered 


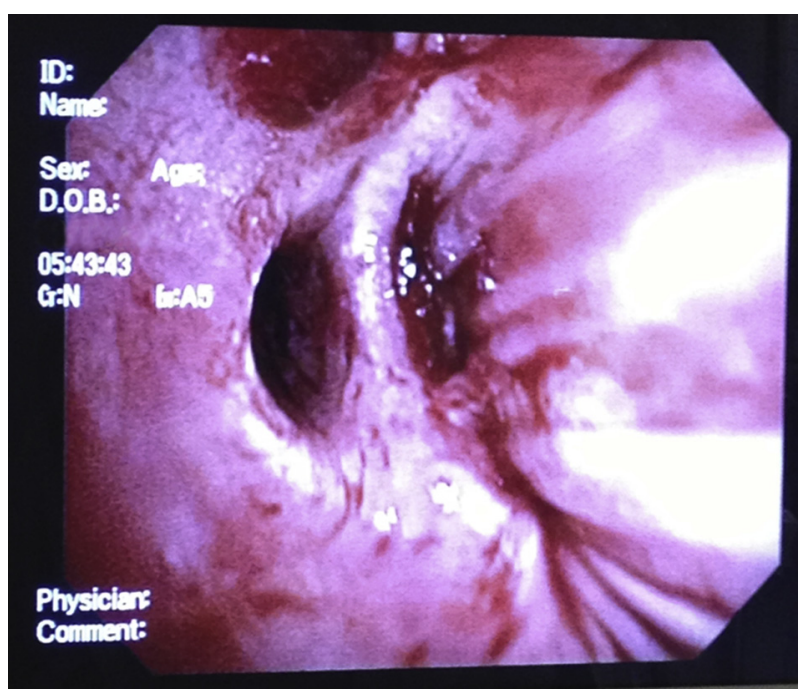

FIGURE 2. Postoperative bronchoscopy. Flexible bronchoscopy shows a sealed fistula with patent right middle lobe orifice.

kidney function and was ambulating without oxygen. At 21 months post-LTX, she died of acute cardiopulmonary failure secondary to degenerative mitral valve pathology.

\section{DISCUSSION}

BPF is a well-documented complication in patients post-lobectomy/pneumonectomy, with an estimated incidence of $1.2 \%$ to $3.1 \%$ and a mortality rate of $27.2 \%$ to $54 \%{ }^{3}$ We present a reliable approach to an uncommon complication. The omental flap was the most important component. We took advantage of the rich vascular supply of the greater omentum, which is also known to have potent angiogenic properties. ${ }^{2}$ Improved neovascularization of bronchial suture lines has been published in animal models, conferring a significant advantage to repair over muscle alone. ${ }^{2}$ Although use of omental flaps is generally considered to be safe, there are potential complications, which include abdominal wall infection, ventral hernia, and fascial dehiscence. $^{4}$

Despite the potentially higher risk for bronchial stump dehiscence because of the dependent nature of a lower lobe stump, we prefer lower lobectomy. On the back table, pulmonary vessels in this setting are not distended with blood flow, making the delineation of the anatomy challenging at times. Thus, lower lobectomy is easier, because fissures are more predictably complete. ${ }^{5}$ Upper lobectomies result in most of the lung parenchyma sitting below the hilar structures, which may create an apical space issue. ${ }^{5}$ An additional concern when performing upper lobar transplantation is the necessity for 2 suture lines: anastomosis and bronchial closure. Lower lobar transplantation (upper lobectomy) has the theoretic advantage of a single suture line at the anastomosis, but the size mismatch leads to other challenges. ${ }^{1}$

\section{CONCLUSIONS}

This approach to repair for a patient after lobar LTX has become our standard practice for this infrequent postoperative complication.

\section{References}

1. Shigemura N, D’Cunha J, Bhama JK, Shiose A, Abou El Ela A, Hackmann A, et al. Lobar lung transplantation: a relevant surgical option in the current era of lung allocation score. Ann Thorac Surg. 2013;96:451-6.

2. D’Andrilli A, Ibrahim M, Andreetti C, Ciccone A, Venuta F, Rendina E. Transdiaphragmatic harvesting of the omentum through thoracotomy for bronchial stump reinforcement. Ann Thorac Surg. 2009;88:212-5.

3. Sirbu H, Busch T, Aleksic I, Schreiner W, Oster O, Dailchau H. Bronchopleural fistula in the surgery of non-small cell lung cancer: incidence, risk, factors, and management. Ann Thorac Cardiovasc Surg. 2001;7:330-6.

4. Hultman C, Carlson G, Losken A, Jones G, Culbertson J, Mackay G, et al. Utility of the Omentum in the reconstruction of complex extraperitoneal wounds and defects: donor-site complications in 135 patients from 1975 to 2000. Ann Surg. 2002;6:782-95.

5. Keating DT, Marasco SF, Negri J, Esmore D, Burton JH, Griffiths AP, et al. Long-term outcomes of cadaveric lobar lung transplantation: helping to maximize resources. J Heart Lung Transplant. 2010;29:439-44. 